\title{
Teachers' Perceptions on Parental Involvement: A Case Study of Two South African Schools
}

\author{
Masiye Makgopa \\ Matseliso Mokhele \\ Department of Curriculum and Instructional Studies, \\ University of South Africa (UNISA), Pretoria 0003 South Africa \\ mokheml@unisa.ac.za
}

Doi:10.5901/jesr.2013.v3n3p219

\begin{abstract}
The importance of a collaborative engagement between parents and teachers in order to enhance learning in the classroom cannot be overemphasised; indeed, the two parties seem inseparable. In this study, the teachers who participated indicated that they need parents' assistance if they are to teach well. On the other hand, the parents themselves are keen to help, since it is the future of their children which is at stake. The challenge that emerges from this situation is that, more often than not, there is a breakdown in communication. As a result, teachers and parents blame each other, especially if the learners do not perform well at the end of a year. The teachers will claim that the parents did not do anything to help their children with their schoolwork, while the parents will insist that the teachers failed to teach. It is of the utmost importance that this "blame game" be stopped and that, instead, both groups help the learners to do well in the classroom. In this paper we explored teachers' perceptions regarding parental involvement. We used qualitative research interviews. We discussed what teachers think parental involvement is and how it should be carried out.These teachers clearly indicated that parents can indeed be of great help, because it is the parents who can influence certain aspects of the learners' lives - aspects to which teachers simply do not have access.
\end{abstract}

Keywords: parental involvement, teacher 'perceptions, teachers' expectations, school work.

\section{Introduction}

Parental involvement is viewed by many researchers in a number of different ways. Bokhorst-Heng (2008) argues that parental involvement comes in various forms and will differ as a child moves through primary and secondary school. She refers to Epstein's (2002) classic six-type model that captures the potential scope of parental involvement as follows: (1) the basic obligations of parents as care-providers; (2) schools communicating with parents about school programmes; (3) parents volunteering at school; (4) parental involvement in home learning; (5) the parent as decision-maker; and (6) parental involvement as community collaboration. The author hinted that, significantly, her model suggests a two-way partnership in which schools support parents and parents support schools towards reaching the common goal of improved student learning.

Hill and Tyson (2009) highlight the fact that, although there is a growing body of literature focusing on parental involvement in education during middle school, to date no systematic research has been carried out to determine what types of involvement have the strongest connection with achievement. Existing research shows that teachers want parents to be involved in their children's education. Conteh and Kawashima (2008) highlight the point that government policy in England has, for many years, encouraged parental involvement in children's education. In response, most primary schools have developed a range of strategies designed to assist parents in supporting their children's learning at home, particularly as far as helping children learn to read is concerned. However, there seems to be a specific way in which teachers expect parents to get involved in their children's education. Lareau (2000), for instance, indicates that teachers and principals do not ask the parents to get involved by intervening and nor do they (i.e. teachers and principals) always appreciate parents' actions. Nevertheless, Lareau found that teachers and principals tolerated and sometimes encouraged parents' interventions at school even when these deviated from school or district rules. The point made by Lareau and other scholars is that the issue of parental involvement in schools is rather a "hit-or-miss" issue, and all parties seem to tolerate a certain amount of "clumsiness". Teachers are not always happy when parents become 
involved, especially in terms of curriculum matters, but they nevertheless sometimes tolerate such parental involvement (albeit with a certain degree of reluctance).

Although the involvement of parents in their children's education is perceived by teachers as important, it is not clear what role the parents are expected to play in the schools. Chen, Kyle \& Mclntyre (2008) argue that teachers are aware of the importance of parental involvement, but the focus is always on concerns about the learners. The abovementioned authors noted that not knowing how to involve parents and not having sufficient time are major constraints that teachers identify as far as expanding or making changes in parental involvement strategies are concerned. Zhao and Akiba (2009) argue that, while in many countries schools play a major role in promoting parental involvement, few comparative studies have examined school expectations for parental involvement and the effect of parental involvement on student achievement. In this paper, we aim to ascertain what teachers expect from parents in order to improve their children's performance in the classroom.

\section{Literature review: The concept of parental involvement}

Various researchers have defined the concept parental involvement on the basis of different perspectives. Lareau (2000) defines parent involvement as "... preparing children for school". This includes activities such as, for example, teaching children the alphabet, talking and reading to children to promote language development, attending school events (e.g. parent-teacher conferences), and fulfilling any requests teachers make of parents (e.g. playing word games with their children at home). Lareau further notes that, although parent involvement is positively linked to school success, many parents are not as involved in their children's schooling as teachers would like them to be. Many teachers work hard to increase the level of parental involvement. Surveys indicated that most teachers want and request parental involvement, particularly in the early years of the child's schooling. Lareau (2000) further notes that almost all the teachers in elementary schools encourage parental involvement and many are discouraged by what they call insufficient parent participation. It appears that there is a serious need for parents and teachers to work closely together if learners are to do well in the classroom.

According to Jeynes (2003) parental involvement consists of four components: parental expectations, parental interest, parental involvement in the school, and the family community. Jeynes further concludes that parental expectations are the most important aspect of all four components and that increased parental involvement is the key to improving children's academic performance. Bower and Griffin (2011) agree with Jeynes's 2003 definition of parental involvement, and argue that the traditional definition of parental involvement includes activities in the school and at home. Parental involvement may take many forms, such as volunteering at the school, communicating with teachers, assisting with homework, and attending school events (e.g. school performances or parent-teacher conferences). These authors go on to define parental involvement as either supporting student academic achievement, or participating in schoolinitiated functions.

\subsection{The importance of parental involvement}

A number of researchers emphasise the importance of parental involvement in the early stages of learning. Senechal and LeFevre (2002), in their investigation of whether parental involvement relates to the development of early literacyskills, found that parents' report of teaching accounted for a significant amount of children's early literacy skills. These authors further suggest that parent-involvement in the attainment of early literacy skills provide the basic groundwork for children's acquisition of the mechanics of reading. They maintain that the notion that including parents in their children's academic development can critically enhance their performance has been supported by research conducted in a variety of research contexts. They further argue that the understanding of how different aspects of parental involvement might influence children's acquisition of reading skills is of great importance. These authors indicate that teachers should recommend that parents read to their children before and after their children begin their decoding skills, because early progress in the development of receptive language is predictive for the acquisition of reading vocabulary and comprehension. In addition to this, Rivera (2010), claims that the children of parents who are involved in their child's early schooling perform better than those whose parents do not participate. Parents who invest time, effort and energy in their children's education convey a compelling message that education is important, and that the child's efforts matter.

In his research Rivera (2010) found that, for Latino parents with limited or negative school experiences, active participation (i.e. as a parent) may seem overwhelming, frightening or intimidating. He further adds that the greater the parents' interaction and involvement, the better the child's performance. Closing the achievement gap must start at home 
with the parents, and should begin when the child is born. Parental involvement is a valuable component of any learner's education. According to DePlanty, Coulter-Kern and Duchane (2007), researchers have found that parent-child discussions about school help to improve academic achievement and reduce problematic behaviour. This finding strongly suggests that parental involvement is a valuable component of any learner's education. DePlanty et al. (2007) further argue that parents are their children's first and most important teachers, and for the learners to succeed in school, parents must participate actively in their children's academic lives.

\title{
3. Research methodology
}

For the purpose of this study, we employed qualitative research approaches. We found the qualitative approach relevant to this study because our research examined teachers' expectations and perceptions of parental involvement. Given that expectations and perceptions cannot be quantified, the qualitative approach was therefore relevant. Qualitative research seeks to understand human and social behaviour from the insider's perspective, that is, as it is lived by participants in a particular social setting (e.g. a culture, school, community, group, or institution (Ary, Jacobs and Razavieh 2002).

Since this is a case study of two schools, the sample consisted of teachers from the two selected primary schools. The sample size was relatively small, since it involved purposeful sampling for a case study of the two schools. We selected 10 teachers from the two schools. The target sample was teachers at the two selected primary schools in the Mogalakwena District. All 10 teachers were interviewed to find out their own expectations of parental involvement in school.

\section{Findings and discussions}

The background to the research is: given that teachers expect parents to be involved in their children's education, how do they expect them to be involved? In other words, what do teachers want parents to do in order to help their children to improve their performance? The premise of this paper is that teachers need to engage with the question of how they would like the parents to be involved in their children's education in order to improve their children's academic performance. In this paper, our primary aim is to explore teachers' perceptions of parental involvement.

We specifically focused on what teachers want parents to do in order to help their children with their schoolwork. To present the findings of our research, we discuss five major findings based on the data we collected. We begin by discussing, firstly, the guidance that is supposed to be given to the children by their parents. Secondly, we shall discuss the encouragement that parents are supposed to give to their children. Thirdly, we shall look at the creation of an environment that is conducive to learning. Fourthly, we shall discuss the essence of the communication that is supposed to take place between teachers and parents. Lastly, we shall discuss how parents can help their children to perform well in the classroom.

\subsection{Importance of parental guidance}

The teachers who were interviewed indicated that parental involvement can indeed help to improve learners' performance. In essence, parents must guide their children to do well in the classroom. All the teachers we interviewed agreed that parents should not do the work for the learners, but should instead help by giving guidance. One of the teachers interviewed noted:

\begin{abstract}
"The parents must guide the learners only when they get stuck. They must not do the work for the learners. They must only guide the learners and the learner must do the work on his/her own. If the parents do the homework for their children, these children will not be learning anything. They will only sit and wait for their parents to do the homework, which they know they will do correctly. The parents must let their kids do the homework on their own and only correct it."
\end{abstract}

On the other hand, teachers expect parents to help when the learners get the answers wrong, and help the children correct them. In other words, parents should not just leave everything to the learners. The teachers we interviewed believe that, with proper guidance from parents, learners will be able to grasp what is taught at school. Parents must not do the work for their children, but they must guide them. They must let them (the learners) do the work and only help when the child needs to be corrected. And parents must correct the child and not just leave him/her to struggle on by themselves, particularly if what the child is doing is incorrect. Parents must also find activities for their children to do, activities that are related to what the learners do at school, and then let their children work on those 
activities. Parents must also correct their children when they fail to do these activities well.

From the quotation above teachers indeed expect parents to guide their children on matters relating to schooling. DePlanty et al. (2007) agree that parental involvement is a valuable component of any student's education. They argue that researchers have found that parent-child discussions about the school help to both improve academic achievement and reduce problematic behaviour. This finding strongly suggests that parental involvement is a valuable component of any learner's education. DePlanty et al. (2007) insist that parents are their children's first and most important teachers, and for students to succeed in school, parents must participate actively in their children's academic lives.

\subsection{Learner encouragement}

The teachers we interviewed stated that parental involvement has to be looked at with a somewhat critical eye. Parents should not only visit the school when their child is experiencing some sort of problem. Some learners are really doing well in class but, nonetheless, these learners still need parental involvement to keep them motivated. Unsurprisingly, these learners' performance tends to deteriorate simply because of their parents' lack of attention. If these learners do not receive any attention from their parents, they are likely to feel neglected and will no point in their efforts. Learners performing well, need to be made to enjoy the privilege of performing better than the other learners. This will definitely boost their self-esteem and make them happy learners. The parents of these children need to be involved - in this case, by encouraging the learners to do even better.

Learners who perform well can be encouraged to do even better by means of incentives (e.g. awards). This is where the parents come in, because teachers interviewed suggested that these parents help to organise award-giving ceremonies. (Parents are in a better position (i.e. than teachers) to do this because they are likely to know local business people who may be willing to sponsor such events. These learners may ultimately develop a sense of competition among themselves. This sort of competition will be beneficial because it will encourage them to continue working hard to maintain the position of top achievers. This sort of competition may also encourage those who are not good achievers to decide to surprise everyone (i.e. by being awarded a class or school prize).

Some learners need encouragement in the form of a little "push from behind". These learners need to realise that their parents expect them to perform well. One teacher indicated that, "if the parents demand to see the work done on that day, this will motivate the child to work harder, because the child will realise that he/she cannot afford to keep on disappointing his/her parents by performing badly. The child will make sure that he/she does not always do badly, because the child realises that someone is watching him/her. This is different from the learner who obtains low scores and gets away with it, simply because no one seems to care whether he/she does well or badly." This is also what the other teacher said:

\footnotetext{
"Yes, absolutely. The parents must play their role by helping and urging their children to do their schoolwork while teachers play their role by teaching the children. Ultimately, as the learners realise that their parents (at home) are behind them as far as their schoolwork is concerned, while teachers (at school) are also behind them, they will definitely work harder. Parents must sometimes demand to see their children's books in order to see what they did at school that day. This also encourages the learner to work even harder, because the learner will soon realise that his/her parents are unlikely to be happy about work that is always of poor quality."
}

If they are to succeed, learners need constant encouragement. Some may not see the importance of making an effort with their schoolwork today. Parents must "be there" for their children, and must realise that they have to encourage their children, and show them that making an effort with schoolwork now will lead to future rewards. Ferrara and Ferrara (2005) argue that parent involvement encourages better school attendance, improved graduation rates and less grade retention, increased parental and student satisfaction with the school, fewer discipline reports, and higher achievement scores in both reading and mathematics. These researchers believe that parents can play a role in their children's education by encouraging them to be obedient, and to perform well academically.

\subsection{Creating an environment that is conducive to learning}

Learners do learn well under conditions that are conducive to learning, and it is the responsibility of the parents to create such an environment. There are several ways in which parents can create such an environment. The teachers who we interviewed indicated that learners need to have an environment in which they feel comfortable if they are to do well in the classroom. These teachers maintained that comfort is essential for learner concentration, and a lack of comfort may result in problems such as poor attentiveness, which obviously leads to poor performance. 
Some parents shout at their children and may even use words that are derogatory. Needless to say, this does their children no good at all. Shouting only makes matters worse. Instead, parents need to talk to their children politely, and explain to them that they (i.e. the children) must use time wisely. This means controlling the amount of television their children are allowed to watch: no child should be allowed to watch television the whole day.

Two of the teachers whom we interviewed also indicated that it is important that learners feel comfortable in the company of their peers. This will reduce the possibility of learners being vulnerable to peer pressure: peer pressure is not always beneficial for some learners. It is extremely painful for a learner to be teased about something he/she has no control over. Indeed, it may be so painful that the learner performs poorly simply because he/she starts to focus on the problem and is no longer able to concentrate on work done in the classroom. In fact, the situation may affect him/her so badly that he or she may decide to leave school. Simple things that can either destroy or make the child include clothing and not having enough money to buy something during lunch break. One of the teachers interviewed noted that:

Besides contributing, by helping the child with homework and other related aspects, the parents must see to it that they create and maintain stability in the lives of their children. This they can do by, namely, buying their children suitable clothing, so that they do not have the problem of peer pressure which may distract their attention in the classroom. They should also give him/her some money to buy something during lunch break. Look, if all the children in his street wear certain designer clothes and it is only he/she who does not, the others are obviously going to tease him/her. As he would not like that, it is likely that he may become a withdrawn person, and obviously this is going to affect his performance in class.

This point is reiterated by Lawson (2003). Lawson claims that, when parents do not provide stable and nurturing home environments, their children come to school ill-prepared, and this obviously makes the teacher's job more difficult. He goes on to say that without a stable home environment, children tend to require additional attention from the teacher and that these children suffer from behavioural and disciplinary problems.

\title{
4.4 Communication between parents and teachers
}

Teachers and parents have a common goal, which is to ensure that learners perform well in their daily activities in the classroom. One can reasonably say that parents and teachers are partners in the process of preparing the youth for the future. This therefore means that they must be in constant communication in their quest to enable children to become responsible adults. Teachers must make time to brief parents about their children's progress in the classroom. Likewise, parents need to make the effort to find out how their children are performing in the classroom. It is not supposed to be a matter of who should first approach whom. Whoever recognises the need to be the first to communicate must take action to ensure that the learner receives help as quickly as possible. Communication between parents and teachers must sometimes include finding strategies that will help the learner. Teachers must not hesitate to make the first move by (where possible) visiting the homes of their learners in order to discuss the learners' progress with their parents. One of the teachers we interviewed indicated that it is important to visit learners' homes so that a relationship of trust can develop between the parents and the teachers, since all are pursuing the same aim, as indicated by of the teachers below:

\begin{abstract}
"Yes, like I have indicated earlier, we write comments on the progress reports for the parents to read, and to do something. Initially we thought that calling parents to come to the school would help a lot, because it would be a face-to-face kind of situation. We sent them (parents) letters to show up at school in order to discuss their kids' performance, but usually that did not work as the parents did not come. Some teachers even went so far as to do home visits where possible. They would visit the learners' home which are near the school. This also had its own challenges, because you may find that the parent is not home, and sometimes you only find an elderly grandparent. Time is also a challenge because the teachers will also be going home after school, and during the day they are supposed to be in the classroom."
\end{abstract}

The importance of communication between parents and teachers cannot be overemphasised. It enables problems to be spotted early, and makes it possible to devise ways of overcoming any challenges a learner may be facing, one teacher noted:

"The parents must get used to visiting the school, and communicate with the teachers of their children. By so doing they will be able to spot the problems early and work on them. It is another matter if the parent is called at the end of the year just to confirm that his child may be retained, as is the case sometimes. The poor child will not have received any help. The problem must be spotted quite early so that several strategies can be applied in order to help the child to pass at the end of the year." 
It is of great importance that teachers keep on communicating with parents, especially on the role that they (i.e. the parents) should play. Parents will not know what teachers expect from them unless teachers make this clear. The importance of communication between teachers and parents was stressed by lzzo et al. in 1999. These researchers maintained that, when parents communicate constructively with teachers and participate in school activities, they gain a clearer understanding of what is expected of their children at school, and these parents are more likely to learn from their children's teachers what they need to do at home to improve their children's education. The advantage gained by communication between these partners, namely the parents and the teachers, is that parental involvement will be informed involvement. These parents will no longer have to "guess" what they are supposed to do to get involved in their children's education; instead, they will have been given relevant information by the teachers. Izzo et al. (1999) indicated that other researchers emphasise the importance of parental actions that children experience directly (e.g. efforts to facilitate the children's academic or social development at home).

\title{
4.5 Every responsible adult has a role to play
}

At different times, parental involvement can take a variety of forms - parental involvement includes input from any parent of any child, irrespective of whether or not the adult is the child's biological parent. Some parents may be unable to help their children owing to their lack of literacy. However, their children still require parental support if they are to perform well in the classroom. Some learners live with their grandparents, and these adults may be unable to read or write. So that these learners were able to receive the same level of help as learners who had literate parents, the teachers who were interviewed decided to group learners together. Learners who live with illiterate grandparents are grouped with those who live with literate parents, so that they can all benefit from parental assistance when they are given work that requires parental help. This is what one of the teachers interviewed said:

\begin{abstract}
"Since in most cases it happens with kids who do not stay with their parents, we normally group learners to do their homework in groups. We find this helpful because if there are learners who stay with parents, in a particular group all the learners in that group will benefit from the help offered by the parents, sisters and brothers. Although, in a group, there will be learners who will benefit as they listen and participate well. There are, however, those who will not benefit because they only copy the work done by the other learners."
\end{abstract}

Some learners are left alone at home for a variety of reasons (e.g. because their parents have gone to seek jobs elsewhere). One of the teachers felt that such children could be helped by retired teachers "adopting" them. Retired teachers could help these children by monitoring their school attendance, making sure they did their homework, and checking to see whether these learners are doing their schoolwork (like their classmates) this was evidenced by one of the teachers:

\begin{abstract}
"Ja, you know the teachers are so desperate to let the parents realize the importance of the role that they can play in order to improve their children's performance. One teacher once suggested that we rope in retired teachers so that they can help. He suggested that we request the retired teachers to adopt the learners. These retired teachers will be requested to adopt learners whose parents are either not there, or are so elderly that they can no longer help the learners. Even incidents where the parents are illiterate are also considered here. These retired teachers will be asked to collaborate with the parents of the identified learners, and will see to it that they do their homework."
\end{abstract}

The teachers who were interviewed emphasised that it must be the responsibility of every adult to be engaged in the process of helping the children to become responsible future citizens. This responsibility should not be the work of teachers alone - everyone must play his/her role. However, parents are expected to play a leading role, since it is the parents who are expected, more than anybody else, to have their children's best interests at heart.

\section{Conclusion}

The teachers we interviewed expected parents to play a number of roles as far as helping their children to perform better in the classroom is concerned. They expect parents to provide a space at home that is suitable for use as a learning environment. Homes are supposed to be peaceful places, places in which the learner can think about his/her schoolwork without being disturbed. Parental arguments and disagreements should not occur in the presence of children. Parents are expected to prepare their children to be ready for the classroom so that teachers can do their job efficiently and effectively. Parental preparation can take the form of teaching children the basic requirements that a learner is expected 
to meet while he/she is at school. Furthermore, teachers expect parents to instil some form of discipline in their children so that these children will know how to behave at school.

Communication between teachers and parents is of prime importance in all of this, because communication, by its very nature, means that teachers can tell parents what they are supposed to do in order to help their children do well at school. Communication also helps to build trust between the two partners, namely the teachers and the parents, both of whom are expected to collaborate in the process of educating the learners in their charge. Parents and teachers have a common aim, which is to ensure that learners succeed in their schoolwork. They must be in constant communication with each other to ensure that parents do not neglect to provide their children with appropriate educational assistance.

In closing, we recommend that the Department of Education make it policy that schools be given the responsibility of making parents aware of their responsibilities in equipping their children with skills that will see them through their adult life-worlds. Parents fail to do what they are supposed to do not because they are ignorant: it is usually because they simply do not understand their educational responsibilities. This is why they tend to shift their responsibilities on to other people. The Department of Education can also make available (at the school) information that clearly sets out parents' responsibilities regarding their children's education.

\section{References}

Ary D, Jacobs LC \& Razavieh A (2002). Introduction to research in education. Belmont, CA: Wadsworth.

Bower HJ \& Griffin D (2011). Can the Epstein Model of parental involvement work in a high-minority, high-poverty elementary school? A Case Study 15(2): 77-87.

Bokhorst-Heng WD 2008. School-home partnership to nurture adolescent literacy. Middle School Journal 39(5): 40-49.

Chen C, Kyle DW \& McIntyre E 2008. Helping teachers work effectively with English language learners and their families. School Community Journal 18(1): 7-15

Conteh J \& Kawashima Y 2008. Diversity in family involvement in children's learning in English primary school: culture, language and identity. English Teaching: Practice and Critique 7(2): 113-125.

DePlanty J, Coulter-Kern R \& Duchane KA 2007 Perceptions of parent involvement in academic achievement. The Journal of Educational Research, July: 361-368.

Ferrara MM \& Ferrara PJ 2005. Parents as partners: raising awareness as a teacher preparation programme. A Journal of Educational Strategies, Issues and Ideas 79(2): 77-81.

Hill NE \& Tyson DF 2009. Parental involvement in the middle school: a meta-analytic assessment of the strategies that promote achievement Developmental Psychological 45(3): 740-763.

Izzo CV, Weissberg RP, Kasprow WJ \& Fendrich M (1999). A longitudinal assessment of teachers' perceptions of parent involvement in children's educational and school performance. American Journal of Community Psychology 27(6): 817-839.

Jeynes WH 2003. A meta-analysis: the effects of parental involvement on minority children's academic achievement. Education and Urban Society 35(2): 202-218.

Lareau A 2000. Home advantage: social class and parental intervention in elementary education. New York: Rowman \& Littlefield.

Lawson MA 2003. School-family relations in context: parent and teacher perceptions of parent involvement. Urban Education 28(2): $77-$ 133.

Rivera M 2010. Parents are key to closing the achievement gap: the Hispanic outlook in higher education 20 (22): 40.

Senechal M \& LeFevre J 2002. Parental involvement in the development of children's reading skill: a five-year longitudinal study. Child Development 73(2): 445-460.

Zhao H, Akiba M 2009. School expectations for parental involvement and student Mathematics achievement: a comparative study of middle schools in the United States and South Korea. A Journal of Comparative and International Education 39(3): 411-428. 
